05

\title{
Гетероструктура SmS/SiC и термовольтаический эффект в ней
}

\author{
() В.В. Каминский, ${ }^{1}$ А.О. Лебедев, ${ }^{1,2}$ С.М. Соловьев, ${ }^{1}$ Н.В. Шаренкова ${ }^{1}$ \\ ${ }^{1}$ Физико-технический институт им. А.Ф. Иофрфе РАН, \\ 194021 Санкт-Петербург, Россия \\ ${ }^{2}$ Санкт-Петербургский государственный электротехнический университет „ЛЭТИ“ им. В.И. Ульянова (Ленина), \\ 197376 Санкт-Петербург, Россия \\ e-mail: Vladimir.Kaminski@mail.ioffe.ru
}

(Поступило в Редакцию 31 мая 2018 г.)

Изготовлена гетероструктура на основе монокристаллического $\mathrm{SiC}$ и поликристаллической тонкой пленки SmS. В температурном интервале от 300 до $456 \mathrm{~K}$ измерен термовольтаический эффект в структуре, максимальная величина которого достигала $\sim 12 \mathrm{mV}$ при $T=456 \mathrm{~K}$. Показано, что величина эффекта соответствует разработанной ранее его концентрационной модели.

DOI: $10.21883 / J T F .2019 .02 .47072 .225-18$

Термовольтаический эффект обнаружен в настоящее время не только в $\mathrm{SmS}[1]$, но и в некоторых других полупроводниках, например, в структурах $p \mathrm{Si}-n\left(\mathrm{Si}_{2}\right)_{1-x}(\mathrm{ZnS})_{x} \quad[2], \quad$ в сэндвич-структурах $\mathrm{ZnO} / \mathrm{ZnOMe}(\mathrm{Me}=\mathrm{Cu}, \mathrm{Fe})[3]$. Исходя из описанного в [4] концентрационного механизма возникновения термовольтаического эффекта, следует, что его наличие можно ожидать в самых разнообразных полупроводниках и полупроводниковых структурах. В настоящей работе была предпринята попытка обнаружения этого эффекта в двухслойной гетероструктуре на основе карбида кремния $\mathrm{SmS} / \mathrm{SiC}$.

Монокристаллическая подложка из карбида кремния политипа 4Н с ориентацией (0001) и размером $15 \times 15 \times 0.35 \mathrm{~mm}$ была изготовлена из слитка $\mathrm{SiC}$, выращенного модифицированным методом Лели (метод ЛЭТИ) при температуре $2200^{\circ} \mathrm{C}$. Легирование донорной примесью производили непосредственно в процессе роста из газовой фазы при добавлении фиксированного количества азота в нейтральную газовую среду (аргон).

Характерный размер областей когерентного рассеяния рентгеновского излучения (ОКР) в направлении (0001) $\mathrm{SiC}$ составлял около $2000 \AA$. Концентрация электронов проводимости при $T=300 \mathrm{~K}$ составляла по оценкам около $3 \cdot 10^{18} \mathrm{~cm}^{-3}$. На поверхность этого монокристалла методом взрывного испарения в вакууме при температуре $500^{\circ} \mathrm{C}$ была нанесена тонкая поликристаллическая пленка сульфида самария толщиной на различных участках от 0.3 до $0.33 \mu \mathrm{m}$. Величина параметра кристаллической решетки $\mathrm{SmS}$ составляла $5.92 \AA$, величина ОКР (область когерентного рассеяния) около $90 \AA$.

Схема измерения термовольтаического эффекта представлена на рис. 1. На нагревателе резистивного типа 1 располагалась медная пластина 2, на которой лежала исследуемая структура таким образом, что монокристаллический слой $\mathrm{SiC} 4$ соприкасался с медной пластиной и был с ней в хорошем электрическом контакте через металлический жидкий слой InGa 3. Токовыводящие контакты 6 располагались на пластинке 2 и слое $\mathrm{SmS} 5$. Выходной сигнал подавался на мультиметр RIGOL DM3061, передавался в ЭВМ посредством соединения RS232 и выводился на экран монитора программой LabVIEW. Результаты измерения приведены на рис 2. Максимальный сигнал $\sim 12 \mathrm{mV}$ наблюдается при температуре $456 \mathrm{~K}$. При выдержке при постоянном значении $T \sim 453 \mathrm{~K}$ сигнал стремился к постоянному значению $\sim 10 \mathrm{mV}$.

Величина электрического напряжения, которая может быть получена в исследуемой структуре за счет термовольтаического эффекта, была оценена на основании полученного нами ранее соотношения, связывающего величину выходного сигнала $U$ с температурой генерации $T$ и параметрами образца $[5,6]$ :

$$
U=\frac{k\left(T-T_{0}\right)}{e} \ln n_{2} / n_{1},
$$

где $T_{0}$ - начальная температура, $n_{1}$ и $n_{2}-$ концентрации электронов проводимости в областях образца вблизи токовыводящих контактов при температуре $T$. Прямое измерение концентрации носителей заряда с помощью эффекта Холла в данном случае не представляется возможным. Обычная концентрация элек-

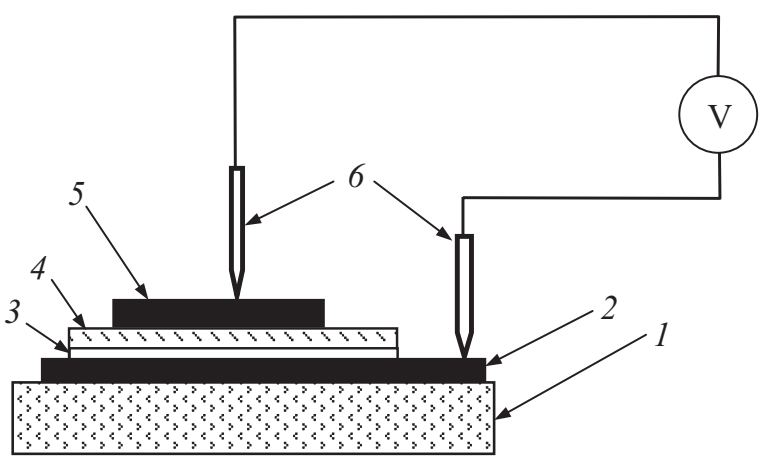

Рис. 1. Схема эксперимента: 1 - нагреватель, $2-$ медная пластина, 3 - слой InGa, 4 - кристалл $\mathrm{SiC}, 5$ - пленка $\mathrm{SmS}$, 6 - прижимные токовыводы, V - вольтметр RIGOL DM3061. 

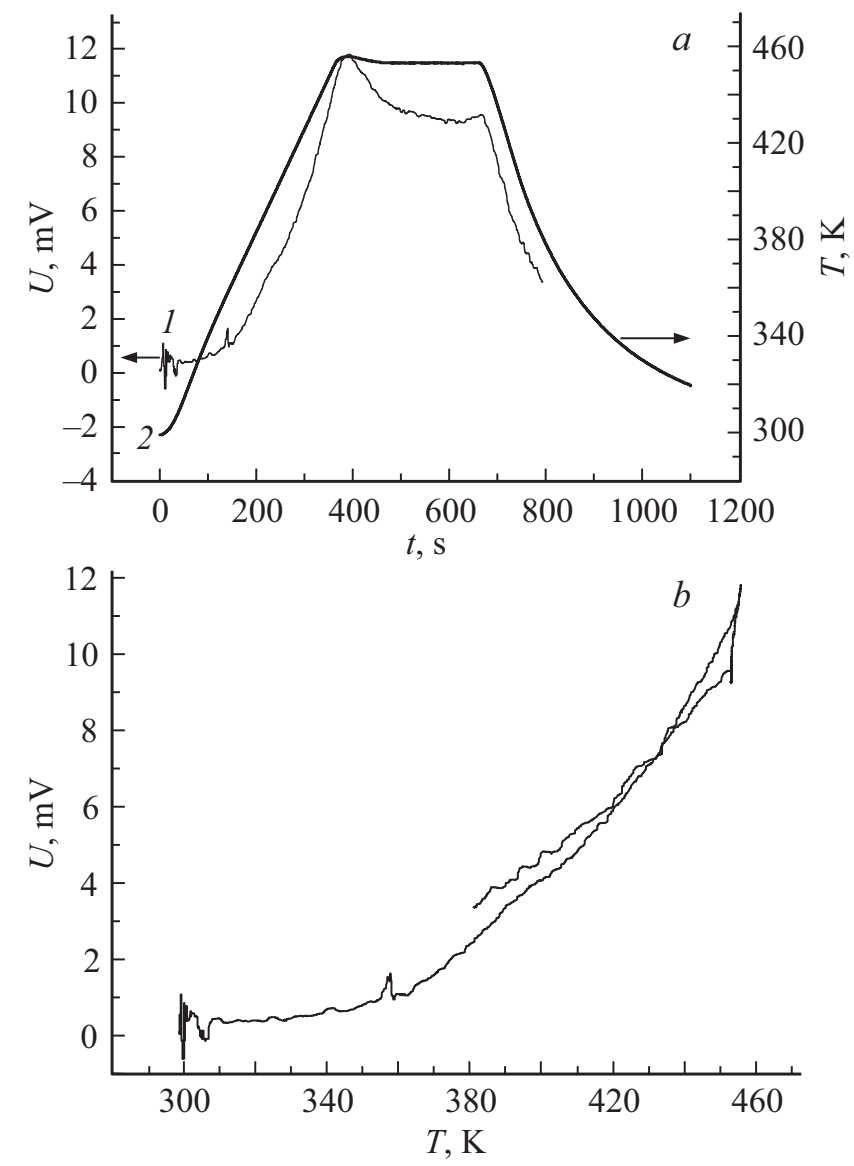

Рис. 2. Электрическое напряжение, генерируемое гетероструктурой $\mathrm{SmS} / \mathrm{SiC} ; a-$ зависимости выходного сигнала (1) и температуры (2) от времени; $b-$ температурная зависимость выходного сигнала термовольтаического эффекта.

тронов проводимости в тонких поликристаллических полупроводниковых пленках $\mathrm{SmS}$ лежит в интервале $10^{19}-10^{20} \mathrm{~cm}^{-3}$ [7]. Поскольку в нашем случае тонкий слой $\mathrm{SmS}$ сформирован на полупроводниковом материале, можно предположить наличие диффузии избыточных ионов $\mathrm{Sm}$ в $\mathrm{SiC}$, так как структура подвергалась нагреву до $500^{\circ} \mathrm{C}$ в течение получаса при ее изготовлении. Поэтому для оценки величины $U$ имеет смысл взять значение $10^{19} \mathrm{~cm}^{-3}$. Тогда из формулы (1) при $T=456 \mathrm{~K}$ мы получаем значение выходного сигнала $16 \mathrm{mV}$. Оно находится в удовлетворительном соответствии с экспериментальным результатом, что свидетельствует в пользу того, что мы имеем дело с термовольтаическим эффектом, а не с эффектом Зеебека. Помимо этого, можно утверждать, что эффект Зеебека не мог бы дать величину сигнала $12 \mathrm{mV}$, так как для этого необходимо создать на толщине образца $0.35 \mathrm{~mm}$ слишком большую разницу температур $75 \mathrm{~K}$ (величина термоЭДС $\mathrm{SiC}$ при $n \sim 10^{18} \mathrm{~cm}^{-3}$ составляет $\left.160 \mu \mathrm{V} / \mathrm{K}[8]\right)$.

Таким образом, на основании полученных результатов можно утверждать, что нами обнаружен термовольтаический эффект в полупроводниковой гетероструктуре
$\mathrm{SmS} / \mathrm{SiC}$. Величина генерируемого напряжения существенно превышает значения, полученные в [2] и [3], но меньше, чем полученная для гетероструктуры $\mathrm{SmS} / \mathrm{EuS}$ $(55 \mathrm{mV})[9]$.

\section{Список литературы}

[1] Каминский В.В., Соловьев С.М. // ФТТ. 2001. Т. 43. Вып. 3. C. 423-426. [Kaminskii V.V., Solov'ev S.M. // Phys. Solid State. 2001. Vol. 43. N 3. P. 439-442.]

[2] Саидов М.С., Саидов А.С., Усмонов Ш.Н., Камонов К.А. // Гелиотехника. 2009. № 4. С. 102-104. [Saidov M.S., Saidov A.S., Usmonov Sh.N., Amonov K.A. // Appl. Sol. Energy. 2009. Vol. 45. N 4. P. 285-286.]

[3] Пронин И.А., Аверин И.А., Баженова А.С. и др. // Письма в ЖТФ. 2015. Т. 41. Вып. 19. С. 23-29. [Pronin I.A., Averin I.A., Bozhinova A.S. at al. // Tech. Phys. Lett. 2015. Vol. 41. N 10. P. 930-932.]

[4] Каминский В.В. // Письма в ЖТФ. 2013. Т. 39. Вып. 15. C. 12-17. [Kaminskii V.V. // Tech. Phys. Lett. 2013. Vol. 39. N 8. P. 673-675.]

[5] Улашкевич Ю.В., Каминский В.В., Казанин М.М. // ФТТ. 2012. Т. 54. Вып. 11. С. 2066-2067. [Ulashkevich Yu.V., Kaminskii V.V., Kazanin M.M. // Phys. Solid State. 2012. Vol. 54. N 11. P. 2198-2200.]

[6] Каминский В.В., Степанов Н.Н., Соловьев С.М. // Физика и техника высоких давлений (ФТВД). 2015. Т. 25. № 3-4. C. $74-81$.

[7] Погарев С.В., Куликова И.И., Гончарова Е.В. и др. // ФТТ. 1981. T. 23. Вып. 2. С. 434-439. [Pogarev S.V., Kulikov I.I., Goncharova E.V. at al. // Phys. Solid State. 1981. Vol. 23. N 2.]

[8] Смирнов И.А., Смирнов Б.И., Мохов Е.Н. и др. // ФТТ. 2008. T. 50. Вып. 8. С. 1355-1358. [Smirnov I.A., Smirnov B.I., Mokhov E.N. at al. // Phys. Solid Stat. 2008. Vol. 50. N 8. P. 1407-141.]

[9] Каминский В.В., Казанин М.М., Романова М.В. и др. // ФТП. 2016. Т. 50. Вып. 9. С. 1163-1166. [Kaminskii V.V., Kazanin M.M., Romanova M.V., Kamenskaya G.A., Sharenkova N.V. // Semiconductors. 2016. Vol. 50. N 9. P. $1141-1144$.] 